Vallentin's article is illustrated by a photograph of a "rookery" of rock-hopper penguins (Eudyptes chrysocome), showing the myriads in which these birds congregate on the coasts, and by a second (herewith reproduced) of a much smaller assemblage of gentu penguins (Pygosceles taeniata). An interesting fact in connection with the habits of the rock-hoppers is that the smooth surfaces of the hard igneous rock over which these penguins have passed for generations are not only highly polished, but are marked by irregular groovings made by their claws. These scratches are usually about 3 inches in length, and may be as much as a quarter of an inch in depth. Apparently such a polished and striated rock-surface might well be attributed to ice-action. A striking feature about such a rookery is the number of dying and maimed birds to be met with; such injuries appear to have been inflicted by seals or sea-lions. The enormous number in which the "mollymauks" frequent the Falkland and other Antarctic islands may be inferred from the statement that on one occasion a vessel arrived at the main port with a cargo of 10,000 eggs of this species. Mr. Vallentin found these beautiful birds so tame and confiding that they allowed themselves to be stroked by his hand as he admired the softness of their plumage and its spotless condition. How these birds keep themselves clean amid the liquid filth of a rookery is little short of a marvel.

R. L.

\section{THE ST. LOUIS INTERNATIONAL ELECTRICAL CONGRESS.}

THIS congress, during its five working days, considered about 160 papers on electrical subjects. In fact, so large was the number of papers and so wide the range of subjects of which they treated, that it may be said that there is no branch of electrical science which was not referred to at one time or another during the meetings. Nevertheless, the chief scientific interest in the proceedings centred round a few subjects, namely, units and standards, radio-activity, wireless telegraphy, and the electric arc. Of the engineering papers, those on the alternating current motor, the steam turbine, and high tension transmission attracted most attention. There were also numerous papers on electrochemical and electrotherapeutical subjects, which will not be referred to here.

The joint discussion by Section A, general theory, and Section B, general applications, on units and standards was opened with papers by Prof. Ascoli (systems of electric units), Profs. Carhart and Patterson (absolute value of the E.M.F. of Clark and Weston cells), and Dr. Wolff (international electric units). The subject divided itself into two parts :(I) the true value of the volt and ampere; (2) which of these should be represented by a material standard, and the nature of that standard. During the discussions the naming of the magnetic units was also considered.

Upon the question of the true value of the volt and ampere there was practical unanimity of opinion that the true value of the volt ( $10^{8}$ C.G.S. units) is such that the E.M.F. of a standard Clark cell at $\mathrm{I}^{\circ} \mathrm{C}$. is very much nearer 1.433 volts than I.434, the present legal value. Profs. Carhart and Patterson, in describing the dynamometer with which they are making a re-determination of the ampere, stated that though the experiments were not sufficiently advanced to give a definite value, the results so far obtained made the E.M.F. of the Clark cell about 1.433 volts, accepting the $\mathrm{ohm}$ as correct. In this connection Mr. Trotter's results, mentioned by Dr. Glazebrook, are of great interest. Mr. Trotter has recently made a determination of the E.M.F. of the Clark cell at the Board of Trade laboratory in terms of the standard ampere and standard ohm, and finds the value to be $x .4329$ volts at $15^{\circ} \mathrm{C}$. It would thus appear that the voltage of a normal Clark cell, determined in terms of our standard ampere and ohm, is nearly I/Io of I per cent. less than the legalised value. The Reichsanstalt take the value of the Clark cell at $I \cdot 4328$ volts. It is of interest to note that the present legal value of $x .434$ appears to be almost exactly correct at $14^{\circ} \mathrm{C}$. instead of $15^{\circ} \mathrm{C}$.

$\mathrm{Mr}$. Barnes, in his paper on the mechanical equivalent of heat measured by electrical means, which contains a very careful comparison of the results obtained both by the electrical and mechanical methods, takes the Clark cell as No. 1826 , vol. 70$]$
I. 43325 volts, and then finds that the "results by the continuous electrical method is brought into absolute agreement with the mean of the mechanical measurements," and he gives the value of the mechanical equivalent as 4.186 joules in terms of the mean calorie between $0^{\circ}$ and $100^{\circ}$.

The standards which are to represent the fundamental electrical units raised quite another set of questions, the main desiderata for these standards being that they should be both permanent and reproducible to a high degree of accuracy. No one appeared anxious to quarrel in any way with the standard mercury ohm, and the agreement of the standards lately made by the National Physical Laboratory, both with one another and with those constructed by the Reichsanstalt, shows that this standard is reproducible to a few parts in 100,000. Accepting the present ohm standard, it is only necessary to legalise a standard for either the ampere or the ohm, as the three units are connected by Ohm's law. Prof. Carhart and Dr. Wolff urged the desirability of defining the voit in terms of a cell, preferably the cadmium cell, and the ampere in terms of the volt and $\mathrm{ohm}$, the advantages being that the standard cell is very generally used in practical measurements both of potential difference and current, and that the cells are reproducible to a high degree of accuracy. Dr. Glazebrook pointed out that the greater simplicity of the chemical changes in the deposition of silver gave promise of its being an even more accurate standard for the ampere.

Prof. Carhart and Mr. Hulett, in their paper on a study of the materials used in standard cells and their preparation, trace the difficulties with cells both of the Clark and Weston (cadmium) type to the mercurous sulphate; they describe an electrolytic method of preparing it, and they strongly emphasise the importance of avoiding hydrolysis of the mercurous sulphate. In a table in the paper they give the results obtained with fourteen cadmium cells made according to their method, from which it appears that the maximum difference between the voltages of in dividual cells and between the voltages of the cells during the whole seven months that the tests lasted did not exceed 5 parts in 100,000 , so that, taking any cell at any time during the tests, its voltage could be depended on to within \pm 0.03 millivolt of the mean voltage. Similar excellent results have been obtained by Mr. Smith at the National Physical Laboratory (report to British Association, Cambridge).

In view of the large amount of work which is now being carried out on the preparation of standard cells and the redetermination of the ampere, the general feeling of the meeting seemed to be that international action to correct the error in the volt should be postponed, although one speaker urged that the error of o.r per cent. in the volt had become of serious commercial importance in the life tests of incandescent lamps.

Prof. Wolff's paper, which dealt largely with the legal definitions of the fundamental units adopted by various nations, pointed out the great differences which exist, and the necessity of rendering them all uniform.

On the subject of naming the magnetic units there was very little discussion; the question of $4 \pi$, of course, came up, and was discreetly left on one side, most of the meeting agreeing with Dr. Kennelly that it is better to let well alone, and that no very great practical advantage would result from the change. The views of the I.E.E. delegates, that if any magnetic units were named they should be those proposed by Dr. Kennelly, viz. the C.G.S. units of magnetic potential (already called the Maxwell at the Paris congress), total magnetic flux, and magnetic reluctance, met with pretty general acceptance. The other proposal made by Dr. Kennelly, namely, to add the prefix " ab" or "abs" to the names of the practical units to forn names for the corresponding C.G.S. units in the electromagnetic and electrostatic systems, so that " abvolt" would be the name for the C.G.S. unit of difference of potential in the electromagnetic system, and absampere for the C.G.S. unit of current in the electrostatic system, led to no discussion, the I.E.E. delegates simply expressing their disapproval of this proposal, which made the same prefix have different numerical values according to the name it preceded.

The chamber of Government delegates, to which Great Britain appointed at the last moment Colonel Crompton. 
Dr. Glazebrook, and Prof. Perry as delegates, also considered the questions of units and standards, and at the concluding meeting of the congress the announcement was made that the chamber of Government delegates had decided to advise their respective Governments to appoint a permanent international commission, consisting of two members from each Government, to secure uniformity in units and nomenclature, and a second committee to deal with the international standardisation of machines, this latter to act by correspondence.

The most interesting paper on radio-activity was that of Prof. Rutherford, who traced one step further his remarkable disintegration theory of radio-activity. Starting with the radium emanation, he traced its disintegration through three stages, which he called radium $\mathrm{A}, \mathrm{B}$, and $\mathrm{C}$, the latter producing by its disintegration $\alpha, \beta$, and $\gamma$ rays. These changes take place fairly rapidly, and the activity dies away approximately following a logarithmic law. There remains behind, however, in the tube which contained the emanation a deposit the activity of which dies away very much more slowly. By dissolving this deposit in sulphuric acid, it can be separated into two parts, the one of which will deposit on a bismuth disc immersed in the liquid, and the second part will remain behind. That which remains behind is found to give out $\beta$ rays only, and is called by Rutherford radium $D$, while that which is deposited on the bismuth disc gives $a$ rays only, and he calls it radium $\mathrm{E}$. $\mathrm{He}$ also finds that there is another way of separating these two substances, namely, by heating the deposit on platinum to $1000^{\circ} \mathrm{C}$., at which temperature the radium $\mathrm{E}$ is volatile and driven off. Regarding the rate of decay of the activity of these two substances, Rutherford estimates that the activity of radium $D$ will fall to half value in about forty years, while that of radium $E$ will require only about one year. By a comparison of the properties of radium E with polonium, Rutherford deduced strong arguments in favour of their identity, and he also considered that radiotellurium was the same. The product radium $\mathrm{D}$ is more uncertain, though it may be radio-lead. If these results are confirmed, and it is proved that polonium, radiotellurium, and radio-lead are all products of the disintegration of the radium atom, a considerable simplification will result, and a step forward in our knowledge of radioactivity has been made.

The papers by Elster and Geitel concerning natural radioactivity of the atmosphere and the earth, and by Prof. McLennan on the radio-activity of mineral oils and natural gases, gave the results of large numbers of tests on the radio-activity of various waters, oils, muds, \&c., from different parts of the earth's surface and from different depths, and they go far to show the omnipresence of radioactivity in the crust of the earth, though they are not yet sufficiently advanced to settle the important question as to whether there exists a large number of radio-active mineraIs in the earth which have not yet been isolated. McLennan deduces from the rate of decay of the emanation the conclusion that the active substances in natural gases, petroleum, spring-water, and mercury are very probably identical with the emanation from radium, and he also mentions that there appears to be present in some samples of crude petroleum an active substance more persistent than the emanation from radium. Is this the radium $\mathrm{D}$ and $\mathrm{E}$ of Rutherford?

It was unfortunate that, whereas three important papers on the arc were taken together in one section, the same time-was selected for Prof. Child to read his arc paper in a different section, so that those interested in arc phenomena could not hear all the papers; added to this, three out of the four arc papers were not in print at the time of the congress, and the acoustical properties of the rooms in which the meetings were held were of the very worst, making it almost impossible to hear the speakers. Prof. Child attempted to explain the phenomena of the arc on a purely ionic basis, which he summarised as follows:- "The current is carried by ions. These ions are produced, first, either within the kathode, because of its high temperature, or at the boundary surface by the impact of the positive ions; second, through the gas by the impact of the atoms on the negative ions at high temperature; and third, at the boundary surface of the anode by the impact of the negative ions." The theory is, however, not very satisfying, as it throws but little light on many important points, more especially the actions going on at the surfaces of contact of the vapour column and electrodes, as he admits. $\mathrm{He}$ also does not attempt to explain the extraordinary effect of slight traces of impurities, which is so marked in the case of the carbon arc that the present writer is of the opinion that with perfectly pure carbon electrodes the carbon arc, as we know it, could not exist.

One of the most interesting facts brought out in Prof. Child's paper is the great importance of the temperature of the kathode, and, as he says, "the essential condition appears to be that the kathode shall be very hot." Prof. Steinmetz entered very fully into the importance of the kathode, and he described the stream of particles which he considered as issuing from it. The existence of this stream, and Steinmetz's view that the re-lighting of the alternating arc is a disruptive phenomenon, received striking confirmation from Prof. Lombadi's stroboscopic photographs of the arc.

Prof. Steinmetz deduced an equation for the relation between the arc-length, P.D., and current from theoretical reasoning, which took the form $\mathrm{V}=a+b(l+c) / \sqrt{\mathrm{A}}$, where $\mathrm{V}$ is the P.D., A the current, and $l$ the arc-length; he applied this equation to the volt-ampere characteristics of the magnetite arc, but the agreement between the observed and calculated values seemed as if it would have been better if Mrs. Ayrton's form of equation had been adopted. The magnetite arc looks as if it has a large future before it, as its efficiency is high and the rate of consumption of the electrodes extremely slow. In this connection Prof. Steinmetz said that he had obtained an efficiency of 0.15 watt per mean spherical C.P. with a titanium arc, but that it was not in a commercial form yet. Mr. Blondel, in his paper on impregnated arc light carbons and lamps, gave (if the figures were not misquoted in the reading) an equally extraordinary result with his new lamp and carbons, namely, a mean hemispherical C.P. of 4800 for a 500 watt 9 ampere lamp, as against 7oo C.P. for an ordinary open arc taking practically the same power.

Dr. Fleming and Dr. de Forest each contributed papers on wireless telegraphy, and Dr. Guthe gave one on coherer action; there was also a highly mathematical paper on the theory by Mr. Stone Stone. Dr. Fleming's paper gave a good general résumé of the subject, but contained very little new matter. The chief interest in de Forest's paper centred in the experiments he describes to prove that the action of his electrolytic receiver is due to polarisation, and not to a heating of the electrolyte as alleged by Fessenden. The electrolytic receiver consists essentially of a very small electrode dipping into an electrolyte, the second electrode being large and connected in series with a cell and telephone. Normally, a very small current flows through the receiver, which is greatly increased directly the oscillations pass through it. Dr. de Forest maintains that this is caused by the oscillations destroying the polarisation at the small electrode, and one of the most conclusive statements he makes in favour of this view is that the small electrode must be made the anode, and that the receiver is practically inoperative if it is connected to the negative of the local battery. This would certainly not be the case if the action depended on the heating of the electrolyte which should be independent of the direction of the local battery.

Dr. Guthe treated at length the theory of the action of the coherer, especially from the electronic point of view. The first step is assumed to be an electrostatic attraction between the metallic particles. The electrons are carried over from the negatively charged metal to the other side, and we have a current carried entirely by the electrons. An increase in the electrical energy produces an increase in the number of electrons, i.e. the current increases while the difference of potential remains constant. This passage of electricity is accompanied by a pressure at right angles to the flow, which pushes aside the molecules of the dielectric which may have been between the metallic particles, and there remains what may be considered as a continuous metallic conductor. Dr. Guthe further extends this theory by considering the ionisation of the gas or dielectric surrounding the metallic particles. Both Dr. Guthe's and Dr. Fleming's papers contain numerous bibliographic refer- 
ences. Dr. Fleming also proposes the name " kumascopes " for all forms of Hertz wave detectors, but it is not a very pleasant sounding term.

Telegraphy over wires was not neglected by the congress, and Dr. Kennelly gave both an excellent theoretical paper on the transmission speed over submarine telegraph cables, and a practical one on high frequency telephonic circuit tests. To test the telephone circuit for effectiveness a known sinusoidal E.M.F. is applied, and the corresponding received current strength is measured; the ratio of these quantities Dr. Kennelly calls the "receiving end impedance" of the circuit at the frequency used (600 $\sim$ in the tests). If this impedance exceeds a certain value, then the circuit will be defective or inoperative. The interesting part of the apparatus is that used for the measurement of the received current; this is accomplished by passing it through a small platinum wire (Fessenden barretter), which it heats, and the change in its resistance is measured.

By this means, using a 3 micron wire, 23 microamperes can be measured, and with a I.7 micron wire in vacuo 3 or 4 microamperes is said to be measurable. For practical tests on telephone switchboards the use of a sensitive reflecting galvanometer, which the above arrangement involves, is not very convenient, so the change in resistance of the platinum wire is observed by putting it in series with a sensitive milliameter and cell. A complete portable apparatus of this kind was described, with which one scaledivision change in deflection of the Weston milliameter corresponded to $\mathrm{I} .4$ milliamperes of superposed alternating current. Curves are given in the paper showing tests of different lengths of cables.

The improvement of telephonic communication by increasing the self-induction of the circuits is receiving considerable attention in the States, and Dr. Hammond Hayes gave some most striking curves illustrating the reduction in attenuation which has been produced by the use of uniformly spaced loading coils on long circuits. The improvement is very much more marked in the case of cables than air wires. The most striking results are those obtained with a standard telephone cable which was heavily loaded so that the added inductance amounted to about 0.6 henry per mile. In this case, from Dr. Hayes's curves the received current was reduced to about $\frac{1}{2}$ per cent. of the transmitted value at a distance of fifty miles with the cable unloaded, whereas with the loaded cable the received current was 7 per cent. Further, the great importance of terminal reflection where the loaded cable joins the transmitting and receiving apparatus is most marked, as by reducing the self-induction of the end loading coils so as to taper it off and avoid a sudden change in the self-induction the received current was increased to about 18 per cent.

It is also very interesting to note how the curves cross one another, so that short lengths of cable give better results without loading, whereas the cable with loading and terminal taper above six miles long produces less attenuation than the unloaded cable, the advantage in favour of the loaded cable increasing with its length.

There were many other papers of great scientific interest; among these may be mentioned Dr. Pender's paper on the magnetic effect of moving charges, which clears up many of the differences which existed between his results and those obtained by Crémieu, and suggests several other interesting problems; Prof. Wilson on condensation nuclei; two papers on the theory of conduction by Prof. Drude and Prof. Richards; and Prof. Arrhenius's paper on the electric charge of the sun.

In conclusion, it must be said that the congress was a complete success, perhaps more so than might have been expected, considering the great distance many of the members had to travel to attend its meetings, and this was greatly due to the indefetigable energy of its organisers, and especially to Prof. Elihu Thomson, the president, Dr. Kennelly, and $\mathrm{Mr}$. Weaver. The attendance at the meetings was good, and if the discussions were not always as full as could be wished, this was not from lack of interest in the papers, but from lack of time. All the foreign members of the congress, irrespective of nationality, were received and entertained in the most hearty manner by their American confrères, fully bearing out the world-wide reputation that America has for hospitality.

W. Duddell.

\section{PHYSIOLOGICAL CHEMISTRY IN THE} UNIVERSITY OF GLASGOW

TOWARDS the close of his introductory lecture to the course of physiology in the University of Glasgow on October 13, Prof. McKendrick said :-

I think there can be little doubt that the next great advance in physiology will be from the side of physiological chemistry. The phenomena of vital activity depend on chemical processes in which there are either the building up of complex substances by the union of simpler ones, or the decomposition of complex bodies into simpler ones-in other words, processes that are of a synthetical or of an analytical nature. These chemical phenomena lead, on the one hand, either to the locking up, or, on the other, to the liberation of energy, and the energy in a living being may appear as mechanical motion, heat, electricity, and to some small extent, and in special cases, as light and sound. During the last sixty years many of the physical phenomena of the living being have been investigated by special methods. It seems to me that we cannot expect much more from the application of the graphic method of registration, nor from the examination of the phenomena of electrical action in living tissues. The microscope and the methods of histological research have left little to be desired as to our knowledge of the structure of the elementary tissues and the structure of organs. A new departure must be made. No method of research seems so inviting or so promising as the rigid and methodical investigation of the chemical phenomena happening in living matter.

Hence the extreme importance of the chemist and the physiologist working hand in hand for the future advancement of physiological knowledge. At one time it was supposed that the chemical phenomena happening in the living body were of a different order from those occurring in dead matter. In 1824, however, Wöhler pointed to the first example of a synthetical process discovered within the animal organism. He showed that when benzoic acid is introduced into the stomach it appears as hippuric acid in one of the excretions, after coupling, probably in the liver, with amido-acetic acid or glycocoll. About the same time Hennell effected the synthesis of alcohol, and Wöhler formed urea from ammonium cyanate. As urea was then known only as a product of the animal organism, its synthesis from inorganic substances, and in the laboratory, was a feat of the first importance. This synthesis was the precursor of many others, so that we have now, at the lowest estimate, between two and three hundred chemical substances found in plant and animal tissues that can also be built up synthetically by the organic chemist. Year by year we are adding to this extensive list. Some of these syntheses are striking examples of the knowledge and skill of the chemists of the present day. Such, to mention one brilliant series, are the artificial productions of the sugars by the labours of Fischer and his pupils. Take, again, the formation of the highly complex body camphor, realised by Komppa and Vorländer. It may not be a day-dream if we contemplate the time when even the starches, fats, and proteids we use in our food may also be artificially formed. Physiological chemists have also done much in the way of studying the chemical changes happening to a substance during its passage through the body, but this is a much more difficult branch of physiological chemistry than even the synthetic production of organic bodies.

And yet we are far from solving the mystery of what we may call vital chemistry. When we think, for example, of the synthetical processes by which the chemist constructs complex bodies hitherto only found in the tissues of plants and animals, the question naturally occurs: how does nature produce these complicated molecules without the use of strong reagents and high temperatures? This aspect of the question has been well discussed by my friend Prof. $\mathrm{R}$. Meldola, first, in an address as president of the chemical section of the British Association at the Ipswich meeting in 1885 , and, second, in an important work, soon to be published, the proof sheets of which he has kindly allowed me to peruse, entitled "The Chemical Synthesis of Vital Products." It is clear from a study of the examples given by Prof. Meldola that the synthetical processes worked out by the chemist in his laboratory are quite unlike those occurring in plant and animal tissues, and yet the result is the 